\title{
Social Inequality in Early Childhood Care and Education Provision in Nigeria: A Review of Literature
}

\author{
Hannah Olubunmi Ajayi, ${ }^{1, *}$ \\ ${ }^{1}$ Institute of Education, Obafemi Awolowo University, Ile- Ife, Nigeria \\ *Correspondence: Institute of Education, Obafemi Awolowo University, Ile-Ife, Nigeria. E-mail: \\ lordofhost2013@gmail.com
}

Received: March 9, $2019 \quad$ Accepted: April 18, $2019 \quad$ Online Published: May 24, 2019

doi:10.5430/wje.v9n3p1

URL: https://doi.org/10.5430/wje.v9n3p1

\begin{abstract}
Early childhood care and education (ECCE) programme has been identified as a strong tool to break the cycle of poverty and effective means to establish the basis for further learning, prevent school drop-out, increase equity of outcomes and overall skill levels; hence all nations of the world call for effective investment in ECCE. Nigeria embraced the idea of ECCE and made it a national agenda by incorporating it into the national policy. The essence is to establish access and equality for children all over the country, irrespective of gender, ethnicity, socio-economic transfer. Looking at the trend or the status of the ECCE for some years, it is as if there are lapses in the provision of early childhood education in the country. The study therefore examined existing research in early childhood education in Nigeria between 2013 and 2017 (which are pre and post Millennium Development Goals documents) to highlight the indicators of enrolment in ECCE, sex, and personnel to determine whether there is equality or inequality in the provision and identify the areas of inequality if there be any. The findings showed that inequality still exists in the provision of the ECCE programme in Nigeria. The enrolment in the programme is still low as compared to other educational levels. Employment of personnel into the programme is also very low to the number at the primary level. There was no visible data on the educational programme as from 2017 . It is recommended that the government should show more commitment to the educational level.
\end{abstract}

Keywords: social inequality, early childhood care and education, provision, Nigeria

\section{Introduction}

The Nigerian government, like other nations, realized the place of early childhood education in the national sustainability hence she became a signatory to the Convention on the Rights of the Child and the Charter of the Rights of African Child. She went further to embrace millennium development goals (MDGs) with attention on MDGs No. 1, 'comprehensive early childhood development...'. Hence, there was a categorical statement that 'education, which should be free, compulsory and universal, is the right of every child'. In the fulfilment of her pledge to the documents and MDGs' agenda, several steps have been taken to show the direction of the arrow. For instance, Child Rights Act was enacted in 2003, for the main purpose of upholding the rights of the Nigerian child, although till date, only twenty- four out of thirty-six states have adopted the Act and passed it into law while twelve states are yet to consider it as something of importance (UNICEF, 2017). The reason(s) behind the reluctance in adopting the Act needs further examination in the best interest of the Nigeria child. Besides, Integrated Early Childhood Development (IECD) policy was formulated in 2007, National Policy on Education was also revised in 2004 and 2014 to incorporate early childhood care and education in all the existing primary schools in the nation.

This is a giant stride already taken by the government of the land. The overarching voice in all the white papers is that the rights of every child should be accorded to them irrespective of sex, ethnicity, religion or disability. This implies that the government of the land aimed at equality in education and that has to begin at the early childhood level. This led to the broadly captioned, 'Leave no Nigerian Behind' in the Nigeria's Vision (The Presidency, 2015; Jayesimi, 2015). It implies that the government has a strong drive for social justice by including the operation of early childhood care and education in basic education. When social justice is upheld in any society, social equality would also be pursued. By social justice, it is defined as the distribution of goods and services through 
state-sponsored social welfare programme, economic justice through access and equal opportunities and political rights and liberties (Fernandez, Hansing, \& de Rojas, 2008) while Nwaokugha and Ndimele, (2018) explained it as any welfare policy put up by a state for the improvement of the quality of lives of the citizens. The welfare is to make things equally available to all citizens irrespective of factors such as sex, age, ethnicity, religion or status. They further reiterated that the state is to first and foremost be responsible for investing in the citizens, after which the citizens will plough back into society. The best and lasting way of investing in citizens is by educating them.

Though, equality in education has been viewed as something that is spurious, with the view that no two persons are equal, based on certain factors such as the intelligential ability. However, Levin (1976) presented four dimensions that may substantiate equality as access (in terms of enrolment or participation in school), survival (completion of a given educational cycle), output (levels of learning by gender) and outcome (in terms of job status or income level). This classification has generated lots of arguments among scholars, while most studies in education have delineated equality in education to having everyone gain access to receiving education without reference to the other three levels of Levin (1976), some argued that it should include the likelihood of completing a given educational cycle and others indicated that equality can be talked about when persons obtained similar levels of knowledge and select occupation that are evenly distributed(Osokoya, nd.). With these arguments, it implies that there is no consensus among scholars as to the indicators of equality. However, whichever of the arguments having the upper hand, this current paper exonerates access as key in explaining equality, without which other variables might not come into being. If there is no access, there cannot be completion, levels of learning as well as job status or income level. Therefore, education is a key variable for social equality and one of the most important and lasting investments that the state can give to her citizen is education, in terms of equality in the provision.

For clear definition of the concept, social equality means that in any society, everyone has equal rights under the law to all social concepts including economic equity in form of access to education among many others, and it is referred to as distributive equality (Miller, 1998; Scanlon, 2000; Fourie, 2011). It is also the equal distribution of social goods and burdens such as income, wealth, opportunity, education and health care. Many scholars have stressed the significance of education in promoting social equality (Holm, Lundhal, Weis, \& Schweisfurth, cited in Cooper 2014) and a society is considered a bastion of social equality when there is no discrimination based on a person's ethnic identity, gender, age, origin, income, religion, health or disability (Wolff, 2017). Where all the variables are missing, then there is inequality. The concept of inequalities as explained by Woodhead, Dornan and Murray (2012) covered a broad spectrum of differences in both household circumstances and child outcomes, which are linked to ethnicity, gender, rural-urban location, and the like. They further stated that inequalities are typically about disparities in resources and power and often link to social exclusion. This is what is to be eliminated in any society that desires growth and development in all ramifications as well as in any egalitarian society like Nigeria. This is, therefore, the main goal of sustainable development goals (SDGs) which is an international agenda. The focus is 'to reduce income inequality', with no one being left behind by 2030, with education as the driver of the goal, it is placed as SDG 4 stating the need to ensure equal access to all levels of education, including early childhood education which has been identified as one of the most cost-effective ways to achieve sustainable development (Britto, 2015).

However, it is further pointed out that the distribution of education either in quality or quantity is highly uneven in many societies and the inequality surfaced in the opportunities provided which are not only individual biased but also social class, territorial regions (urban/rural). In any society where this is perpetrated, there may not be a tangible development either that of individuals or society. It is a means of increasing poverty and illiteracy rates. Gale (2014) stated that it is an avenue to increase economic disparities between haves and have-not. To reduce, if not eliminated the disparities is to be more committed to the education of citizens without any prejudice and it has to be from early childhood level. Since Nigeria is an egalitarian society, social equality needs to be esteemed as it has been identified as the strong ideal for any egalitarian society.

Therefore, if the policy statement of 2014 is anything to go by, the education database in Nigeria as at 2014, there are 62,406 public primary schools (Nairaland, 2016). The implication is that in 2014, there should be nothing less than 62,406 early childhood education centres as well in Nigeria. Now that the nation is four years into SDGs implementation, the questions that come to the mind are: what is the status of ECE in Nigeria? Is there social equality in the provision? Will 2030 be a reality for the Nigerian 3 to 5-year old children? This is the thrust of this study.

\subsection{Aim of the Research}

The aim of the research is to assess the status of early childhood education provision in Nigeria determining whether there is social equality/inequality in the provision to other educational system based on information made available. 
For establishing social justice and transparency, giving necessary information on the government' efforts in fighting or eliminating social inequality of any face especially in the area of education is expected to be made open so that the procedure of achieving 2030 SDGs agenda may be monitored by all and sundry. In order to probe into the study, four objectives were set.

\subsection{Objectives}

Objectives of this study are as follows:

$>$ Examine the status of ECCE Centres (in terms of number) in Nigeria between 2013 and 2017.

$>$ Assess children between 3 and 5years accessibility to early childhood education programme in Nigeria between 2013 and 2017 in terms of enrolment, sex?

$>$ Determine equality in children's access based on gender within the study periods?

$>$ Examine the availability of personnel with their sex within the study periods?

From the objectives, the following research questions were asked:

i. Are there early childhood education centres in Nigeria between 2013 and 2017 ?

ii. Do children between 3 and 5 years have access to early childhood education in Nigeria between 2013 and 2017 in terms of enrolment, sex?

iii. Is there equality in the children's access based on schools - ECCE and Primary within the study periods?

iv. Are there personnel for the educational levels within the study periods?

\section{Method}

The current study adopted a comprehensive systematic review of research. This research design is taking to be appropriate because it is acclaimed to be a critical tool for documenting the evidence base on early childhood interventions that may help in making policy and program decisions (Mathematica Policy Research, 2018).

\subsection{Subjects for the Study}

Since the study is a systematic review, articles on Nigeria education, with a focus on early childhood education in form of studies published basically online in refereed journals, technical reports from National Commissions and Agencies or dissertations served as population and out of which articles on early childhood education which focused basically on access (in terms of enrolment, sex, and personnel) between 2013 and 2017 were eligible for the review. Data were collected from National Bureau Statistics, Nairametrics (2015), NBS: Universal Basic Public Education and Key Statistics in Nigeria - Proshare (2016) that met the criteria.

\subsection{Subject Characteristics}

Published articles used were from journals and technical reports that focused mainly on the provision of early childhood education in terms of access, enrolment, sex of children and personnel were used for the study. Only those that are within the last five (2013 -2017) were used for the study. The articles and reports are either government or early childhood education professional and agencies documents.

\subsection{Sampling Procedures}

The sampling procedure adopted for the study was a purposive one. Only articles and technical reports that were published online for public attention were selected. Articles on Nigeria education, with a focus on early childhood education in form of studies published online in refereed journals, technical reports from National, Commissions and Agencies or dissertations that were within the 2013 - 2017 which were two pre- MDGs and two post-MDGs years were purposively selected.

\subsection{Data Collection Procedure and Analysis}

As a systematic review, the study is consisted of the statistical analysis of the documents gathered online. The data were collected and then conveyed to SPSS for basic statistical analysis, the data were analysed and presented in Bar Charts and percentage.

\section{Results and Discussion}

The results are presented in Tables and Figures in line with the stated objectives for the study. 
Research Question 1: Are there early childhood education centres in Nigeria between 2013 and 2017 ?

The Bar Chart in Figure 1 answers the question.

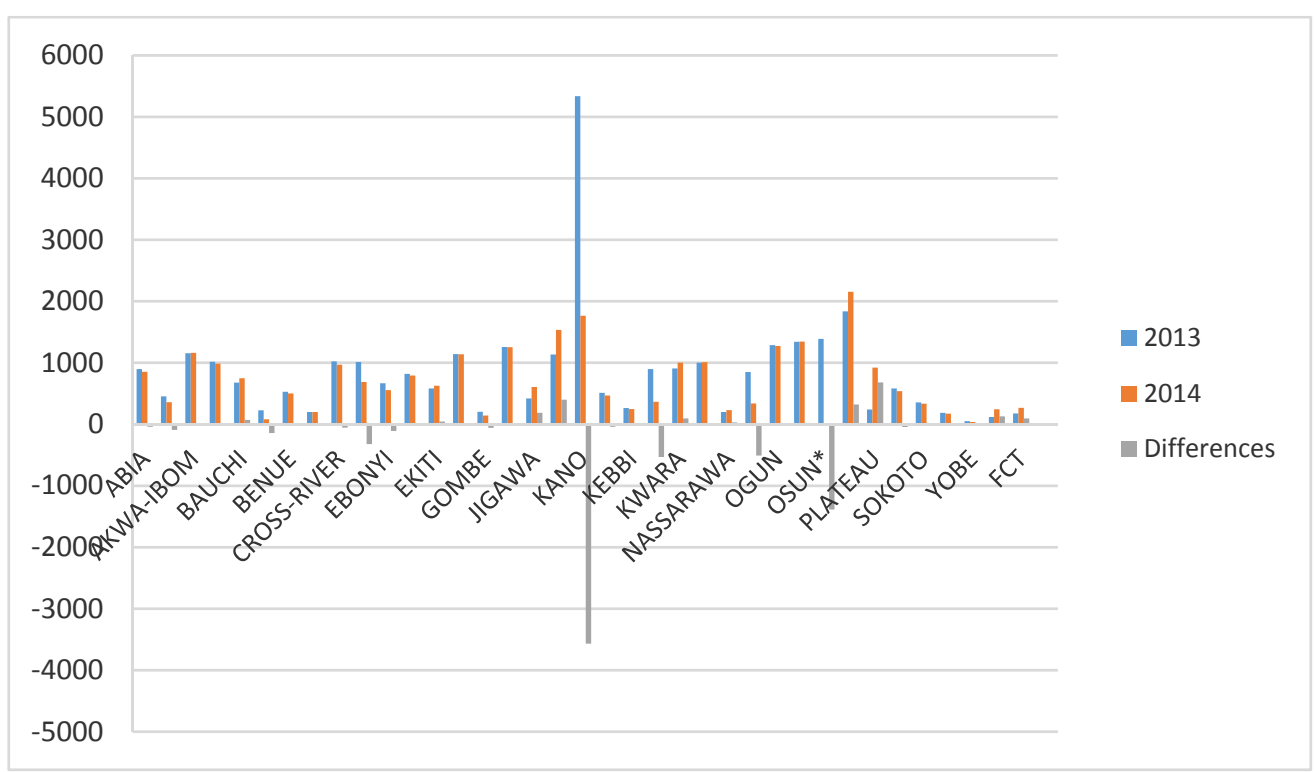

Figure 1. Number of Public ECCDE Centres by State from 2013 to 2017

Figure 1 shows the number of public ECCDE Centres by state from 2013 to 2014 and the differences. The figure indicated that Kano State has the highest rise in the number of ECCDE centres in 2013 with 5,335 followed by Oyo State with 1,835 ECCDE centres. However, the same Kano State had the highest fall in the differences from 2013 to 2014 by 3,570 centres followed by Osun State with 1389 centres of the number she started with. Borno is the only state with no rise nor fall in the number of ECCDE centre between 2013 and 2014. Information is only available in literature for 2013 and 2014, years before MDGs, while from 2015 to 2017, no explicit national record for this level was found.

Research Question 2: Do children between 3 and 5 years have access to early childhood education in Nigeria between 2013 and 2017 in terms of enrolment, sex?

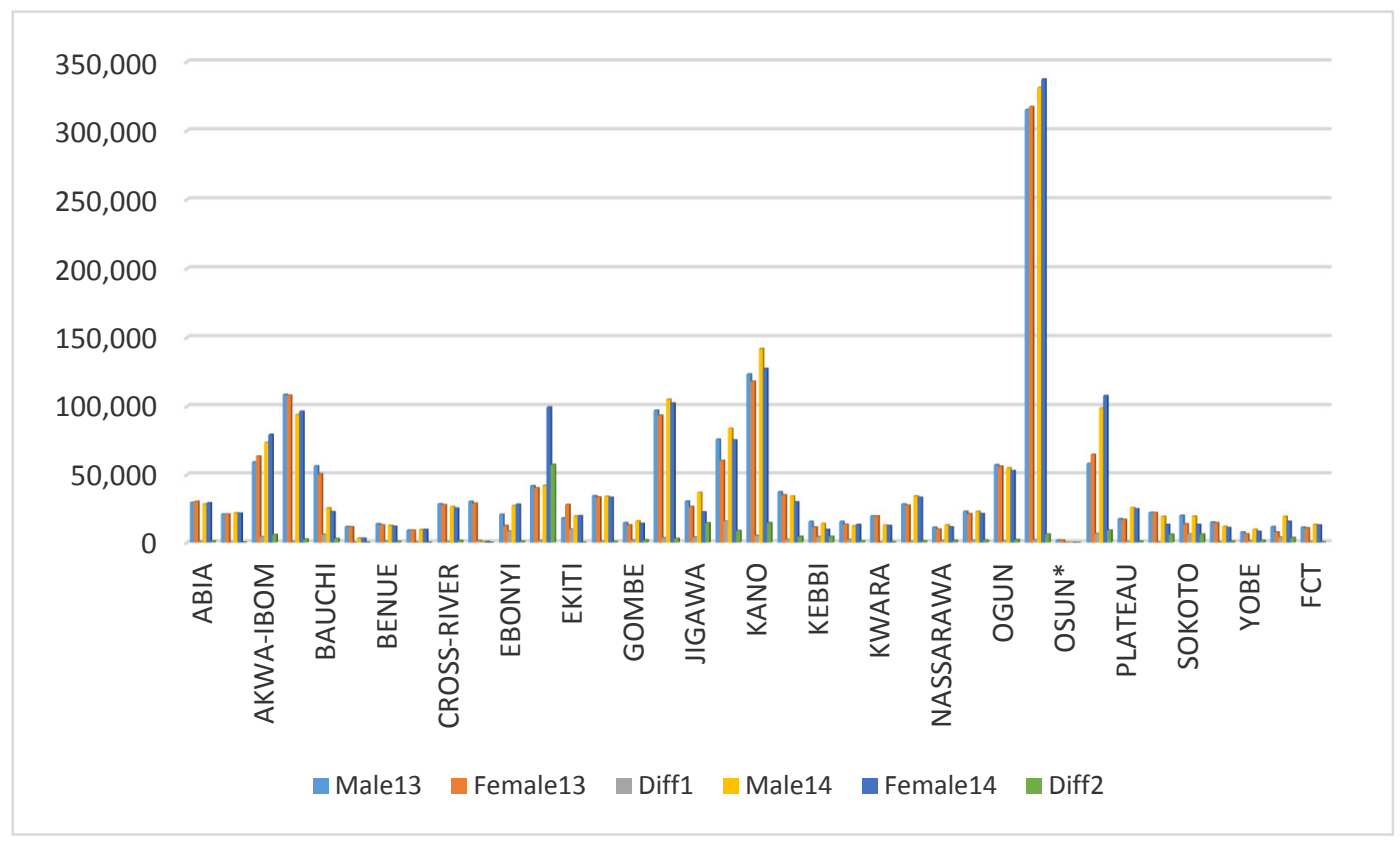

Figure 2. Public ECCDE Enrolment by State and Sex 
Figure 2 shows the public ECCDE enrolment by state and sex in 2013 and 2014 as well as the differences in enrolment of male and female for each year. Ondo State had the highest number of enrolments for male and female with $315,165(\mathrm{M})$ and $317,317(\mathrm{~F})$ for 2013; 331,222(M) and 337,272(F) for 2014; Kano State had 123,389(M); $118,217(\mathrm{~F})$ in 2013; 141,866(M), 127,301(F) and Anambra State had 108,585(M); 108,040(F) in 2013; 93,944(M); 96,298(F). But for 2015 to 2017, there were no national information

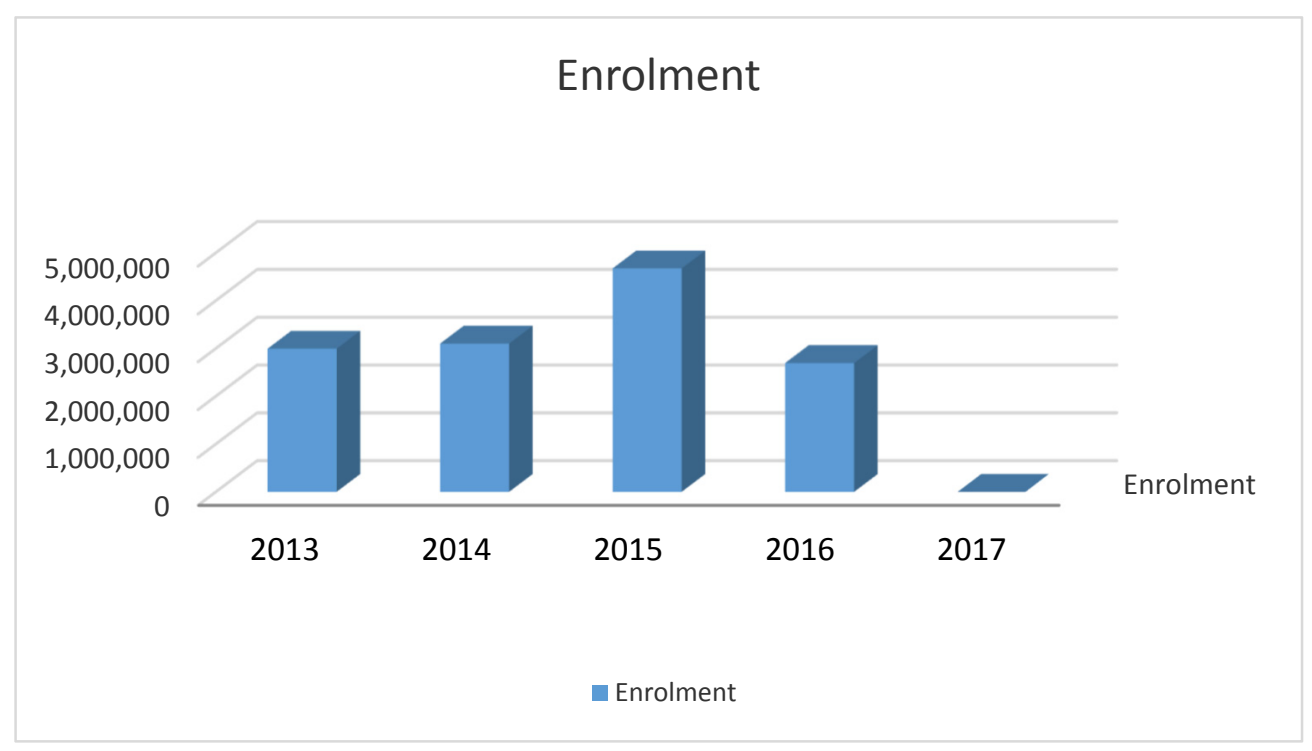

Figure 3. Total Enrolment in ECCDE Centres in Nigeria between 2013 and 2017

Figure 3 shows the total enrolment in ECCDE centres in Nigeria between 2013 and 2017. The Fig. showed that year 2015 witnessed the highest total enrolment figure of 4,672,908 in ECCDE centres in Nigeria as against 2016 with 2,694,787 total enrolment. There was no record for 2017.

Research Question 3: Is there equality in the children's access based on school (ECCE vs Primary) within the study periods?

Table 1. Comparison between ECCE Centres and Public Primary Schools in Nigeria

\begin{tabular}{llll}
\hline & ECCE Centres & Public Primary Schools & \% Difference \\
\hline Number & 28,026 & 62,406 & $44.9 \%$ \\
Enrolment & $2,694,787$ & $25,591,181$ & $10.5 \%$ \\
Sex & (M) $1,548,523$ & (M) $13,435,940$ & $11.5 \%$ \\
& $(\mathrm{~F}) 1,553,019$ & (F) $12,155,241$ & $12.8 \%$ \\
Teachers & 56,588 & 574,579 & $9.8 \%$ \\
\hline
\end{tabular}

Table 1 shows comparison of ECCE and primary school variables of number, sex, enrolment and teachers. A wide gap exists in the provision of ECCE and primary schooling. 44.9\% of ECCE centres existed in Nigeria based on the government database. Only $10.5 \%$ are the children in the centres compared to primary schools. $11.5 \%$ are the male children and $12.8 \%$ are the female. $9.8 \%$ are the teachers handling the children compare to what obtained in the primary sector.

Research Question 4: Are there personnel for the educational levels within the study periods? 


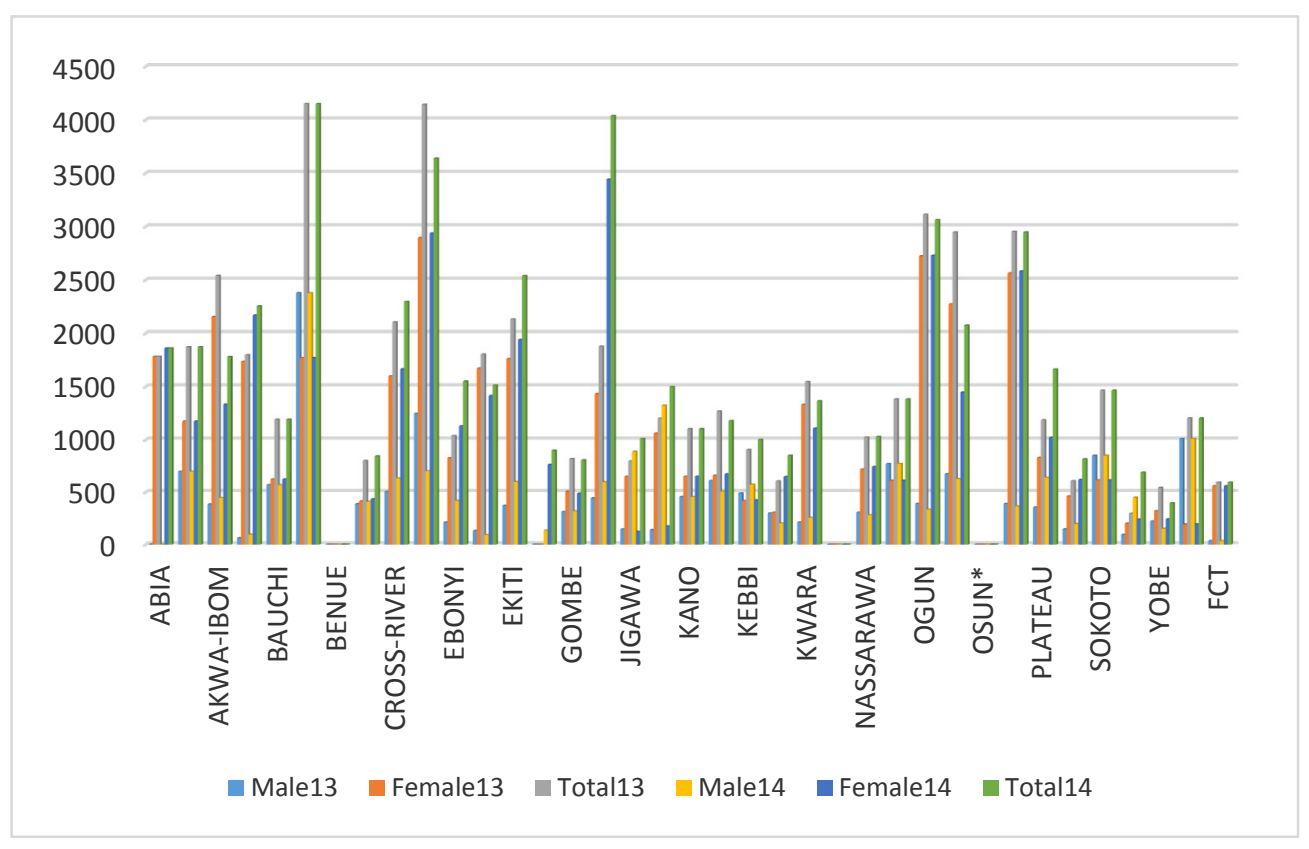

Figure 4. Number of Public ECCDE Teachers by Year and State

Figure 4 shows the number of public ECCDE teachers by year and state. The figure revealed that Bayelsa State has the highest number of ECCDE teachers in both years 2013 and 2014 with a total of 4,150 teachers in 2013 and 2014 followed by Delta state with a total of 4,144 teachers in year 2013 and 3,639 in the year 2014 in that order. No information is gathered on enrolment after 2014.

\section{Discussion}

The finding showed that there is still great disparity in the provision of the ECCE programme in Nigeria. This is in line with UNICEF Reports cited by Warami (2018) that twenty million of 22million Nigerian children aged $0-5$ do not have access to early childhood education, the access was said to still be uneven (UNICEF, nd). Though the reason proffered for the low participation in some areas such as the Northern part of the country was as a result of insurgency.

From the review of literature, the finding showed that there was no tangible record on ECCE in Nigeria after Millennium Development Goals and the action may not be too good for proper planning and decision making on ECCE. This corroborated the report given by Centre for Public Impact (2017) which indicated that children aged 3 5 years are the main beneficiary of the programme under Universal Basic Education but no further information was captured in terms of enrolments, participation, retention or even completion as focus was given basically to primary and secondary education. The report even stated that enrolment dwindled after MDGs - 2015 not only in the insurgency zones.

The finding also showed that there was no explicit national data on ECCDE after 2014. Though another finding showed that year the 2015 witnessed the highest total enrolment figure in ECCDE centres in Nigeria as against what entailed in 2016, the actual breakdown as for 2013 and 2014 was not anywhere available to really show the trend. Pathetically, no data were available on ECCE in 2017 for any state in the country. This just reiterated the report on the poor status and neglect of ECCDE in Nigeria which led to the call for the federal government to invest in the level so as not to put the children at risk of underdevelopment, both physically and mentally (UNICEF cited in Ogune, 2017; Omeje, 2017).

Again, the finding showed that there was a wide gap between the number of ECCDE centres and the primary schools with ECCDE having the lowest number. The finding corroborated Humphreys and Crawfurd (2014) finding that very few children participated in pre-primary education. The implication is that the policy statement has not been followed, there supposed to be an equal number of ECCDE centres with the primary schools and that could have been able to capture the $65 \%$ of children who have not been able to attend organized preprimary education as pointed 
out by UNICEF cited in Omeje (2017) that only 35\% are enjoying the opportunity. So also, from the finding, it showed that teachers of ECCE were not sufficient as compared with the primary level.

\section{Implications of the Findings}

The implications of the findings indicate that the children in this age cohort in Nigeria are already marginalized resulting in social inequality, which is inequality of opportunities that is, the unequal distribution of life chances across individuals in measures such as level of education (Crossman, 2019). If the situation should persist, the possibility of increasing the number of out-of-school in Nigeria would be high. There would also not be a transition to primary one level as proposed in the National policy which effect is gradually trickling down. The report of low enrolments into primary level is already being recorded in research. Again, private sectors are being given the opportunity to extort the low-income group of the society and by this social class is being created for the rich to get richer while the poor become poorer. If the situation is allowed to continue the way it is in Nigeria, the SDG 4 of equality in education may not be realized at the expiration of 2030 .

\section{Conclusion and Recommendations}

Social inequality brings retrogression to any society in all areas of development. This has been the case in many countries of the world, especially the developing countries like Nigeria where poverty pervades the land. Education has been identified as a tool for breaking the cycle of poverty and that is the reason for the global agenda of Goal 1 in the defunct Millennium Development Goals (MDGs) and Goal 4 in the current Sustainable Development Goals (SDGs). Early childhood education has been identified in the SDGs as a strong tool to break the cycle, hence the call to investing in the level to achieve sustainability in any society. Since Nigeria could not meet up with MDGs goal in 2015, and SDGs set time seems a distance now, action needs to be taken early in Nigeria in order to achieve the vision of social equality of 'no child left behind by 2030 through monitoring of the trend. Through the review of literature, the paper has therefore established that there existed social inequality in the provision of early childhood care and education in Nigeria with the government playing a partisan role. If action is not taken early, 2030 may come and still not meet up with the target. It is therefore recommended that the government should of necessity give attention to the provision of the educational level to all children in Nigeria as not all parents could afford the fees being charged at the private schools. The implementation of the policy statement on the establishment of ECE classes in all the existing primary schools should be followed up by the agencies that are in charge of such matters. Every state of the nation should made to comply with national policy so that children in one area would not be backward or left behind. Civil societies in education and social justice should mount up an advocacy campaign to pressurize government towards investing in early childhood education than what is in vogue. The funding which is currently embedded in the financing of basic education with a focus on primary and secondary education should be separated to afford more direct commitment to the educational level.

\section{References}

Britto, P. (2015). A historic moment for early childhood development. UNICEF Connect. https://blogs.unicef.org/blog/a-historic-moment-for-early-childhood-development

Centre for Public Impact (2017). Case Study: Universal Basic Education in Nigeria. Retrieved from www.centreforpublicimpact.org

Cooper, Q. (2014). Does education promote social equality? Retrieved from https://www.nordforsk.org/en/news/does-education-promote-social-equality

Crossman, A. (2019). The Sociology of Social Inequality. Retrieved from https://www.thoughtco.com/sociology-of-social-inequality-3026287

Fernandez, D., Hansing, K., \& de Rojas, A. (2008). Social justice in Cuba: Now and in the future. A Conference Report. Retrieved from http://cri.fiu.edu/research/commissioned-reports/social-justice-fernandez-Hansing.pdf

Fourie, C. (2011). What is social equality? An analysis of status equality as a strongly egalitarian ideal. Res Publica, 18(2), 107-126. https://doi.org/10.1007/s11158-011-9162-2

Gale, T. (2014). Relating Social Inequality and Education Disadvantage: An assessment of pop and policy texts. Keynote address delivered to the ACAL 2014 annual conference Gold Coast, Queensland, 3-4 October, 2014. Retrieved

from 
http://www.acal.edu.au/14conf/docs/Relating-Social-\%20Inequality-and-Education-Disadvantage.pdf

Humfreys \& Crawfurd. (2014). Review of the literature on Basic Education in Nigeria: Issues of Access, equity and Impact. EDOREN.

Ifijeh, M. (2017). UNICEF Calls for Adoption of Child Rights Acts in All States. This Day, June 1, 2017. Retrieved from https://www.thisdaylive.com/index.php/2017/06/01/unicef-calls-for-adoption-of-child-rights-acts-in-all-states

Jadesimi, A. (2015). Nigeria and the Sustainable Development Goals: Setting the Course to 2030. Retrieved fromh ttps://www.forbes.com

Levin, H. M. (1976). Educational Opportunity and Social inequality in Western Europe. Social Problem, 24(2), 148-172. https://doi.org/10.1525/sp.1976.24.2.03a00020

Mathematica Policy Research. (2018). Systematic Evidence Reviews. Retrieved from https://www.mathematica-mpr.com

Miller, D. (1998). Equality and Justice. In Mason, A. (Ed.), In Ideals of Equality. Oxford: Blackwell.

Nairaland Forum (2016). Number of Public Primary Schools in Nigeria According to Zones - Education. Retrieved from http://www.nairaland.com

Nairametrics, (2015). Number of Early Childhood Care and Development Education (ECCDE) Centres in Nigeria 2014. Retrieved from https://nairametrics.com

Nwaokugha, D. O., \& Ndimele, G. (2018). Early childhood education and care: Reliable instrument for achieving social justice in Nigeria. Journal of Education and Practice, 9(24), 29-37.

Ogune, M. (2017). UNICEF charges government on early childhood development. The Vanguard. Retrieved from http://vanguard.ng/news

Omeje, C. (2017). UNICEF sets three ambitious goals for Nigeria on early childhood development. International Centre for Investigative Reporting. https://www.icirnigeria.org/unicef-sets-three-ambitious-goals-nigeria-early-childhood-development

Osokoya, I. O. (nd). Equalizing educational opportunities: The goal of 2004 national policy in education. www.globalacademicgroup.com

Proshare, Economy (2016). NBS: Universal Basic Public Education and Key Statistics in Nigeria. Retrieved from https://www.proshareng.com/news/NigeriaEconomy/NBS--Universal

Scanlon, T. M. (2000). The diversity of objections to inequality. In Clayton, M. \& Williams A. (Eds.), The Ideal of Equality. London: Macmillan.

The Presidency (FRN, 2015). Nigeria's Road to SDGs: Country Transition Strategy. Retrieved from www.ng.undp.org/content/dam/nigeria/docs/IclusiveGrwth/Nigeria

UNICEF, (nd). UNICEF Annual Report 2013-Nigeria. Retrieved from http://www.unicef.org/about/annualreport/files/Nigeria_COAR_2013

Warami, U. (2018). True picture of our public schools: Challenge for govt, foundations. Vanguard News Nigeria. Retrieved from http://www.vanguardngr.com

Wolff, J. (2017). Forms of Differential Social Inclusion. Social Philosophy and Policy, 34, 164-185.

Woodhead, M., Dornan \& Murray. (2012). What Inequality Means for Children: Evidence from Young Lives. ADDRESSING INEQUALITIES: The Heart of the Post--2015 Development Agenda and the Future We Want for All Global Thematic Consultation. 